\title{
Disseminated Coccidioidomycosis with Clinically Evident Splenomegaly in an Immunocompetent Host, First Case Reported in the Literature
}

\author{
Garrett R. Bird*, Robert D. Libke, John F. Billelo, Nancy A. Parks, \\ John S. Pollard
}

\begin{abstract}
Coccidioidomycosis is a dimorphic fungus endemic to the southwestern United States, Central and South America. We report a case of a previously healthy person who presented with respiratory failure and disseminated Coccidioidomycosis who eventually had a fatal outcome. Coccidioidomycosis, or "Valley Fever" has been called the "great imitator" (1) as it can have a wide variety of clinical presentations. This case is unique as it represents the first described case of an immunocompetent host with rapidly progressing, disseminated coccidioidomycosis with clinically apparent splenomegaly and hepatomegaly.
\end{abstract}

\section{INTRODUCTION}

Coccidioidomycosis was initially identified and classified incorrectly as a protozoan species in 1892 by Alejandro Posadas,(2) It was reclassified as a fungus in 1900(3) but retained the name due to its close resemblance to the protozoan coccidian. The two species which cause human disease, C. immitis and C. posadasii, are named for the seriousness of the disease (immitis, latin: not mild) and in homage to Alejandro Posadas. Alejandro Posadas' initial case, a 36 year old Argentinean soldier, eventually died from the disease in 1898. Lesions, at autopsy, were found in his lungs, adrenals, lymph nodes, liver, peritoneum, prostate, spleen, and testes.(4)

Disseminated coccidioidomycosis is a regional disease which has national importance.(5) Coccidioides is a dimorphic fungus endemic to the southwestern United States as well as Central and South America.(6) Outbreaks have also been described well outside the generally accepted borders. Some are due to travel to endemic areas(7-15), while others represent expansion of the known borders of Coccidioidomycosis (16) Coccidioidomycosis causes a range of clinical

*To whom correspondence should be addressed:

Garrett Bird MD, CM

UCSF Fresno

Pulmonary Medicine Department

Community regional Medical Center

2823 Fresno Street

Fresno, CA 93721

gbird@fresno.ucsf.edu presentations from asymptomatic disease, a mild selflimited respiratory disease (17) to dissemination to multiple systems and organs. Dissemination, especially fungemia, (18-20) can lead quickly to sepsis and death.

Coccidioidomycosisis is usually acquired via exposure to dust from soil containing spores. Once inhaled the spores take 1-3 weeks to germinate and cause disease. It is not spread via human to human contact and outbreaks are highly dependent on environmental conditions. Dry, hot summers after a wet winter and spring, increase the number of reported cases.(21) It is common in the Southern California region and, in some endemic San Joaquin valley areas, $75 \%$ of the population has immunity against the fungus as measured by skin testing (22).

Disseminated disease is likely to be seen in certain populations; The infection and dissemination rate is much higher among Blacks and Filipinos (23). Males are infected more often than females (24), which may be exposure based, but may also be related to hormonal or genetic factors. HIV patients (especially with CD4 counts $<100)(25-28)$ as well as patients on chronic immunosuppression for other medical conditions (rheumatological and/or transplant related diseases) and those treated with immunosuppressive chemotherapy are at higher risk of either reactivation of a latent infection or disseminated disease (29-35). Diabetes, which does appear to increase the risk for symptomatic infection and may increase the risk for dissemination (36). 
The disseminated form of Coccidioidomycosis may present with evidence of involvement of the skin (19, 37 ), prostate gland (38-43), eye $(44,45)$, bone (46), meninges (47-49) and liver (50-56). Splenic and hepatic involvement, as diagnosed on autopsy, has been described previously (4) but clinically evident hepatosplenomegaly in a living adult patient has not been widely reported. We present a case of a healthy adult HIV seronegative patient with massive hepatosplenomegaly from disseminated cocci.

\section{CASE PRESENTATION}

The patient was an incarcerated 24 year old African American male who presented to the Emergency Department (ED) from a correctional facility where he had served four months of his sentence. He had been participating in a work-release program during which he was responsible for cleaning up camp sites, national forest sites, and roadways, where it is suspected that he came into contact with soil containing spores of coccidioidomycosis.

His chief complaint was anorexia and rare vomiting for approximately two months. He had begun experiencing worsening general malaise, a ten pound weight loss and had become increasingly short of breath with an occasional cough.

The patient stated that he used alcohol occasionally and had an approximately three-pack-year history of smoking, which he stopped a few years ago. The patient also admitted to drug use (marijuana and methamphetamine) before his incarceration. He had no prior hospital admissions and had been in excellent health until two months before admission. He took no medications regularly and had no allergies. He denied any recent sexual contact. Prior to his incarceration he stated that he was in a stable relationship with his girlfriend.

His maternal family had sickle cell trait, but he and his sister were negative for sickle cell trait or disease. His paternal family history was unknown.

On initial evaluation his blood pressure was 110/60, respiratory rate 41 , temperature 38.3 , heart rate 134 , saturation $98 \%$ on 15 Liters $\mathrm{O} 2$ on a non-rebreather mask with bilateral crackles. His initial physical exam was otherwise notable for an enlarged liver and spleen with a spleen tip palpable at 8 centimeters below the lateral rib margin. He had two cafe-au-lait spots on his anterior abdomen but his exam was otherwise negative. Rectal and Guaiac exams were also negative.

His initial labs were as follows: Sodium 126, potassium 5.1, chloride 98, bicarb 18, BUN 25, creatinine 1.4, glucose 89 , calcium 7.7, Phosphorus 4.3. Hemoglobin 4.9, hematocrit 16.1, white blood cell count 17.9, platelet count 98,000, MCV 72. Arterial blood gas: pH 7.49, PCO2 24, $\mathrm{PO} 2$ 111, bicarb 18, CO2 19. Iron 9 , iron saturation $5 \%$. iron binding capacity 118 with generous iron stores on bone marrow biopsy. Bilirubin was 2.4, direct bilirubin 1.2, indirect bilirubin 1.2, alkaline phosphatase 192, ALT 76, AST 85. Further workup during his admission included a negative ELISA HIV test and his CD4 count was 384 (during his illness). His sedimentation rate was 55. A hemoglobin electrophoresis was performed which revealed no $\mathrm{Hgb} \mathrm{S}$, Hgb A1 90.5\%, A2 3.7\%, F 5.4\%. A serum protein electropheresis showed no monoclonal region. Pneumocystis jiroveci (previously carinii) direct fluorescent antibody was negative. Blood cultures were initially negative on admission. Cryptococcal antigen was negative in a cerebrospinal fluid sample. Sputum acid fast bacilli staining was negative and the samples were culture negative. Legionella urinary antigen was negative.

A Computerized tomography (CT) scan showed hepatosplenomegaly with a miliary infiltrate in both organs.

He initially refused intubation but as he became more fatigued from his tachypnea he eventually consented. His tachycardia and tachypnea were initially thought to be due to his severe anemia and burden of his underlying disease. He was transferred to the Intensive Care Unit (ICU) where he progressed to acute respiratory distress syndrome (ARDS). He was initially given Azithromycin $500 \mathrm{mg}$ a day, Piperacillin/ Tazobactam 3.375 grams IV every 8 hours, and Vancomycin $1250 \mathrm{mg}$ IV every 12 hours. His initial hemoglobin and low platelets prompted a bone marrow biopsy on day 3 which showed Coccidioidomycosis spherules. He also had a positive endotracheal aspirate for methicillin sensitive staph aureus. When the spherules were described on the bone marrow aspirate, and confirmed with serological testing, he was started on Fluconazole $600 \mathrm{mg}$ every day and given Nafcillin 2 grams IV every 4 hours. Fungal blood cultures eventually grew coccidioides. When he did not improve after 4 days he was switched to amphotericin for one dose then to liposomal amphotericin which caused acute renal failure. (BUN 77, Cr 3.5). His course was also complicated by a ventilator associated pseudomonas pneumonia which was treated with Piperacillin/Tazobactam 2.25 grams every 6 hours and Levofloxacin $500 \mathrm{mg}$ IV every 6 hours. His anemia was recalcitrant to multiple transfusions and he had minor bleeding from multiple sites.

The patient developed a board-like abdomen and a perforated viscus was suspected. An exploratory laparotomy was performed on hospital day 13. No perforation was identified but the spleen and liver appeared irregular and were infiltrated with large fungal 
colonies on biopsy. Given the massive splenic involvement which was felt to be compressing his diaphragm and affecting his pulmonary function, a splenectomy was performed. His spleen is pictured below (Figures 1-3). It measured $25 \mathrm{~cm}$ by $18 \mathrm{~cm}$ by $14.5 \mathrm{~cm}$, weighed almost 9 pounds and had visible coccidioidomycosis colonies on macroscopic exam. The pathology slides also confirmed colonies of coccidioides (Figures 4-5). Despite antibiotic and antifungal treatment, after a total of 18 days he developed a cardiac arrhythmia and died on ventilatory support.

\section{DISCUSSION}

Splenomegaly is an uncommon finding in disseminated cocci, especially in an immunocompetent person. Our review of the literature was unable to find any previously reported cases of clinically evident splenomegally in an immunompetent host. We hope that other similar cases will continue to be reported so that further insight into this disease process may be gleaned.

This case highlights many of the problems commonly encountered in patients with Coccidioidomycosis infections: delay to diagnosis, low suspicion with diagnosis suggested from peripheral tests, and seriousness in African American males. The uncommon features are also notable; his rapid progression to ARDS, sepsis and death, his negative HIV ELISA and his relatively appropriate CD4 count along with no significant past medical history are not commonly encountered in a case this severe. This case highlights the importance of considering Coccidioidomycosis and other mycotic diseases when presented with a patient in respiratory failure, even when they are not immunosuppresed.

\section{REFERENCES}

1. Huntington, RW, Jr., Coccidioidomycosis - a great imitator disease. Arch Pathol Lab Med, 1986. 110(3): p. 182.

2. Posada, A., Un nuevo caso de micosis fungoidea con psorospermias. Ann Circulo Medico Argentino, 1892. 15: p. 585-597.

3. Ophuls W, Moffitt H. A new pathogenic mould (formerly described as a protozoan Coccidioides immitis pyogenes): Preliminary report. Phila Med., 1900. 5: p. 1471-1472.

4. Posada, A.Psorospermiose infectante généralisée. Rev Chir Paris, 1900. 21: p. 277-82.

5. Galgiani, JN. Coccidioidomycosis: a regional disease of national importance. Rethinking approaches for control. Ann Intern Med, 1999. 130(4 Pt 1): p. 293-300.

6. Laniado-Laborin, R. Expanding understanding of epidemiology of coccidioidomycosis in the Western Hemisphere. Ann N Y Acad Sci, 2007.

7. Desai, SA. et al., Coccidioidomycosis in non-endemic areas: a case series. Respir Med, 2001. 95(4): p. 305-9.

8. Hughes, CW, and Kvale PA, Pleural effusion in Michigan caused by Coccidioides immitis after travel to an endemic area. Henry Ford Hosp Med J, 1989. 37(1): p. 47-9.

9. Woo, JH, et al. A case of disseminated coccidioidomycosis autopsy report. J Korean Med Sci, 1996. 11(3): p. 258-64.

10. Zalatnai A, Zala J, and Sandor G, Coccidioidomycosis in Hungary. The first import case. Pathol Oncol Res, 1998. 4(2): p. 147-51.

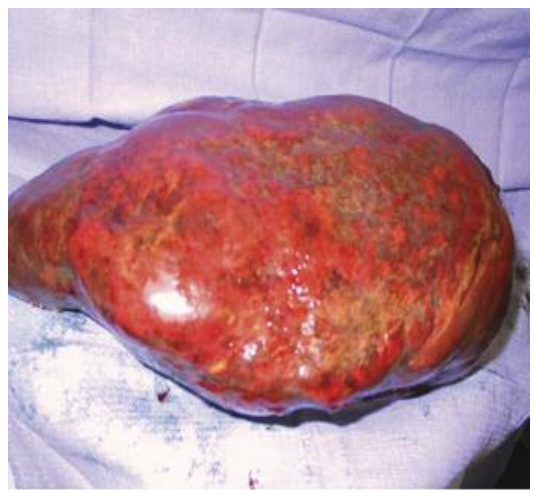

Figure 1: Gross spleen

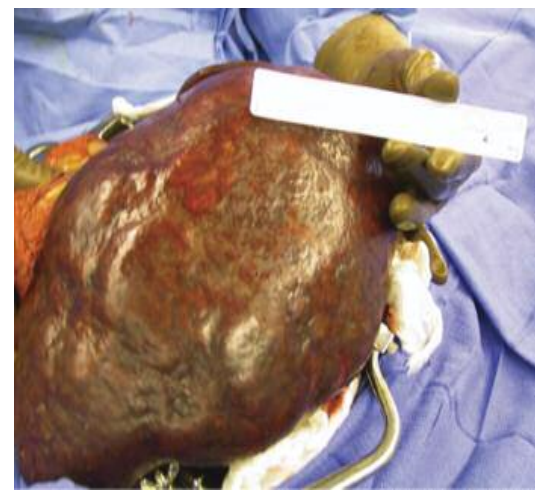

Figure 2: Gross spleen

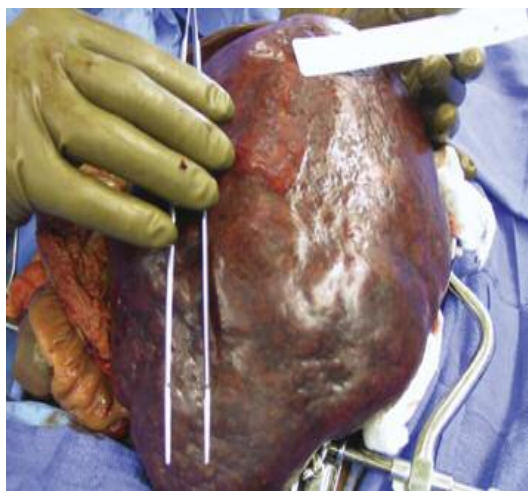

Figure 3: Gross spleen
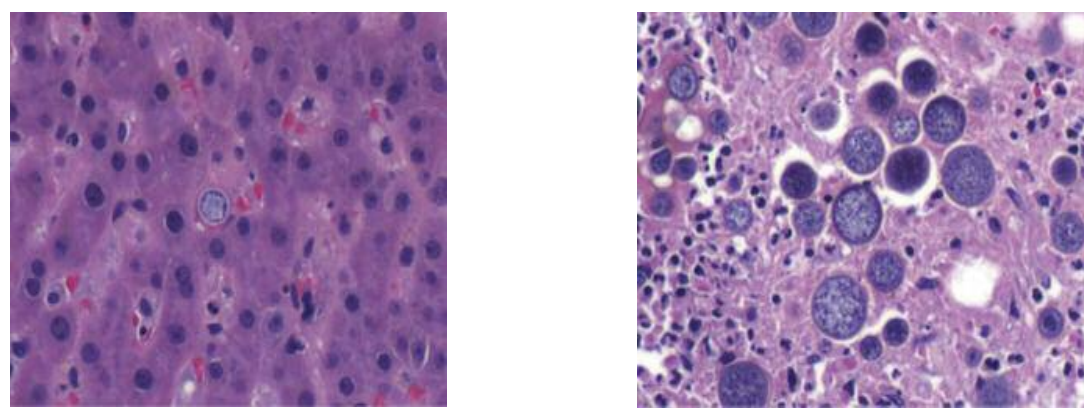

Figure 5: The

spleen is effaced (white pulp and red pulp are not distinguishable) and acute inflammation (neutrophils) is present in the background indicating acute splenitis. Numerous Cocci spherules are present

Figure 4: Liver with a Cocci spherule 
11. Cairns L et al. Outbreak of coccidioidomycosis in Washington state residents returning from Mexico. Clin Infect Dis, 2000. 30(1): p. $61-4$.

12. Coccidioidomycosis among persons attending the world championship of model airplane flying - Kern County, California, October 2001. MMWR Morb Mortal Wkly Rep, 2001. 50(49): p. 1106-7.

13. Chaturvedi V et al. Coccidioidomycosis in New York State. Emerg Infect Dis, 2000. 6(1): p. 25-9.

14. Choon, S.E. and J.J. Khoo, Coccidioidomycosis in malaysia. Br J Dermatol, 1999. 140(3): p. 557-8.

15. Long JB, Brett AS, Horvath JA. Coccidioidomycosis diagnosed in South Carolina. South Med J, 2005. 98(9): p. 930-2.

16. Coccidioidomycosis in workers at an archeologic site Dinosaur National Monument, Utah, June-July 2001. MMWR Morb Mortal Wkly Rep, 2001. 50(45): p. 1005-8.

17. Smith CE et al. Varieties of coccidioidal infection in relation to the epidemiology and control of the diseases. Am J Public Health, 1946. 36: p. 1394-1402.

18. Ampel NM et al. Fungemia due to Coccidioides immitis. An analysis of 16 episodes in 15 patients and a review of the literature. Medicine (Baltimore), 1986. 65(5): p. 312-21.

19. Crum NF. Disseminated coccidioidomycosis with cutaneous lesions clinically mimicking mycosis fungoides. Int $\mathrm{J}$ Dermatol, 2005. 44(11): p. 958-60.

20. Rempe $\mathrm{S}$ et al. Coccidioides immitis fungemia: clinical features and survival in 33 adult patients. Heart Lung, 2007. 36(1): p. 64-71.

21. Smith $\mathrm{C}$ et al. Effect of season and dust control on coccidioidomycosis. JAMA, 1946. 132: p. 833-8.

22. Hicks MJ, Hagaman RM, Barbee RA. The prevalence of cellular immunity to coccidioidomycosis in a highly endemic area. West J Med, 1986. 144(4): p. 425-8.

23. Crum NF et al. Coccidioidomycosis: a descriptive survey of a reemerging disease. Clinical characteristics and current controversies. Medicine (Baltimore), 2004. 83(3): p. 149-75.

24. Ampel NM et al. Coccidioidomycosis in Arizona: increase in incidence from 1990 to 1995. Clin Infect Dis, 1998. 27(6): p. 1528-30.

25. Ampel NM. Coccidioidomycosis in persons infected with HIV type 1. Clin Infect Dis, 2005. 41(8): p. 1174-8.

26. Ampel NM, Dols CL, Galgiani JN. Coccidioidomycosis during human immunodeficiency virus infection: results of a prospective study in a coccidioidal endemic area. Am J Med, 1993. 94(3): p. 235-40.

27. Arsura EL, Kilgore WB. Miliary coccidioidomycosis in the immunocompetent. Chest, 2000. 117(2): p. 404-9.

28. Minamoto G, and Armstrong D. Fungal infections in AIDS Histoplasmosis and coccidioidomycosis. Infect Dis Clin North Am, 1988. 2(2): p. 447-56.

29. Blair JE, Smilack JD, Caples SM. Coccidioidomycosis in patients with hematologic malignancies. Arch Intern Med, 2005. 165(1): p. 113-7.

30. Blair JE. Coccidioidomycosis in liver transplantation. Liver Transpl, 2006. 12(1): p. 31-9.

31. Blair JE, Douglas DD. Coccidioidomycosis in liver transplant recipients relocating to an endemic area. Dig Dis Sci, 2004. 49(11-12): p. 1981-5.

32. Bergstrom L et al. Increased risk of coccidioidomycosis in patients treated with tumor necrosis factor alpha antagonists.
Arthritis Rheum, 2004. 50(6): p. 1959-66.

33. Rosen PP. Opportunistic fungal infections in patients with neoplastic diseases. Pathol Annu, 1976. 11: p. 255-315.

34. Tripathy $U$ et al. Donor transfer of pulmonary coccidioidomycosis in lung transplantation. Ann Thorac Surg, 2002. 73(1): p. 306-8.

35. Wright PW et al. Donor-related coccidioidomycosis in organ transplant recipients. Clin Infect Dis, 2003. 37(9): p. 1265-9.

36. Santelli AC, Blair JE, Roust LR. Coccidioidomycosis in patients with diabetes mellitus. Am J Med, 2006. 119(11): p. 964-9.

37. Rixford E, Gilchrist T. Two cases of protozoan (coccidioidal) infection of the skin and other organs. Johns Hopkins Hosp Rep, 1896. 10: p. 209-68.

38. Bellin HJ Bhagavan BS. Coccidioidomycosis of the prostate gland. Report of a case and review of the literature. Arch Pathol, 1973. 96(2): p. 114-7.

39. Chen KT, Schiff JJ. Coccidioidomycosis of prostate. Urology, 1985. 25(1): p. 82-4.

40. Lawrence MA et al. Coccidioidomycosis prostatitis associated with prostate cancer. BJU Int, 1999. 84(3): p. 372-3.

41. Niku SD, Dalgleish G, Devendra G. Coccidioidomycosis of the prostate gland. Urology, 1998. 52(1): p. 127.

42. Price MJ, Lewis EL, Carmalt JE. Coccidioidomycosis of prostate gland. Urology, 1982. 19(6): p. 653-5.

43. Sung JP, Sun SS, Crutchlow PF. Coccidioidomycosis of the prostate gland and its therapy. J Urol, 1979. 121(1): p. 127-8.

44. Blumenkranz MS, Stevens DA. Endogenous coccidioidal endophthalmitis. Ophthalmology, 1980. 87(10): p. 974-84.

45. Ugurlu $\mathrm{S}$ et al. Coccidioidomycosis of the eyelid. Ophthal Plast Reconstr Surg, 2005. 21(2): p. 157-9.

46. Huang JI, Seeger LL, Jones NF. Coccidioidomycosis fungal infection in the hand mimicking a metacarpal enchondroma. J Hand Surg (Br), 2000. 25(5): p. 475-7.

47. Miller L et al. Coccidioidal meningitis. IMJ Ill Med J, 1985. 167(3): p. 207-8.

48. Bouza E et al. Coccidioidal meningitis. An analysis of thirtyone cases and review of the literature. Medicine (Baltimore), 1981. 60(3): p. 139-72.

49. Vincent $\mathrm{T}$ et al. The natural history of coccidioidal meningitis: VA-Armed Forces cooperative studies, 1955-1958. Clin Infect Dis, 1993. 16(2): p. 247-54.

50. Coodley EL. Disseminated coccidioidomycosis: diagnosis by liver biopsy. Gastroenterology, 1967. 53(6): p. 947-52.

51. Craig JR, Hillberg RH, Balchum OJ. Disseminated coccidioidomycosis. Diagnosis by needle biopsy of liver. West J Med, 1975. 122(2): p. 171-4.

52. Howard PF, Smith JW. Diagnosis of disseminated coccidioidomycosis by liver biopsy. Arch Intern Med, 1983. 143(7): p. 1335-8

53. Maekelt GA. Diagnostic procedures in the evaluation of hepatic diseases. Studies to determine mycotic etiology. Lab Res Methods Biol Med, 1983. 7: p. 141-4.

54. Terplan M. Hepatic granulomas of unknown cause presenting with fever. Am J Gastroenterol, 1971. 55(1): p. 43-9.

55. Thomas $\mathrm{S}$ et al. Coccidioidomycosis presenting as liver abscess. Indian J Gastroenterol, 2001. 20(3): p. 113-4.

56. Ward JR, Hunter RC. Disseminated coccidioidomycosis demonstrated by needle biopsy of the liver. Ann Intern Med, 1958. 48(1): p. 157-63.

Garrett R. Bird MD, CM (Class of 2005) is currently a second year Pulmonary Disease and Critical Care Fellow at UCSF Fresno. He served as both a PR director and senior editor for the MJM while attending McGill. His current research includes end-of-life communication in the ICU, resident education, and advance directives. 


\section{INSTRUCTIONS TO AUTHORS}

The McGill Journal of Medicine (MJM) provides an international forum for student contributions to the field of medicine. We publish student research ranging from basic laboratory science to clinical work to humanities analyses of medicine in society to medically related artwork. Our goal is to reach our broad international readership with multiple perspectives of medicine. The McGill Journal of Medicine currently accepts submissions of the following types: original articles, review articles, letters, research letters, case reports, "crossroads" articles in the humanities, as well as artwork. These are defined below. All submissions must adhere to the following three criteria where applicable:

\section{AUTHORSHIP}

The student must be first author. Authors should have participated sufficiently in the work to take public responsibility for the content. Editors may require contributors to justify the assignment of authorship. Manuscripts submitted to the MJM must contain original work not previously published elsewhere.

\section{MANUSCRIPT STYLE}

The MJM conforms to the style defined in the CBE Style Manual, 5th ed., Council of Biology Editors, Inc., Bethesda, MD, 1983.

\section{TYPES OF ARTICLES}

\section{Non-peer reviewed}

Letter to the $M J M$ - short comment on a specific topic, on a paper previously published in the MJM, or on the MJM itself. Unsolicited letters are welcome.

Commentary - longer than letters but generally consisting of fewer than 700 words, on a topic of general interest. Unsolicited Commentaries are welcome but authors should contact the Editorin-Chief to discuss the topic before submitting.

Focus Article - solicited articles on a subject chosen in advance by the Editorial Board.

Book Review - comments on a book of general interest. Recently published books are preferred but older books still considered to have wide appeal are appropriate. Unsolicited book reviews are welcome but potential authors should contact the Editor-in-Chief to discuss the book before submitting.

Artwork - originals or digital can be submitted

Peer reviewed (First author must be a student)

Original Article - full-length article reporting the results of an original research project. In addition to presenting the project and its findings, the project's rationale and the significance of its findings must be clearly explained.

Case Report - report and discussion of a clinical case that illustrates some important teaching points. Authors must clearly explain the significance of the chosen case and the teaching points illustrated by it.

Review Article - overview of the understanding and outstanding questions in a particular field of research. Review articles that explore a specific hypothesis and/or combine information from different areas of research to advance an original idea are especially encouraged, as opposed to review articles that simply enumerate past findings.

Crossroads - similar in style to review articles. "Crossroads" articles should explore the relationship between medicine and the humanities (visual arts, literature, history, philosophy, etc.).

\section{ORGANIZATION}

For all peer reviewed articles, each required component should begin on a new page and appear sequentially, as follows. Original articles: title page, abstract and key words, introduction, methods, results, discussion, acknowledgements, references, tables and figure titles and figure legends. Case report: title page, introduction, the case, discussion, acknowledgments, references, and tables. Review and "Crossroads" articles: title page, introduction, body of text, conclusion, acknowledgments, references, tables, and illustrations. Figures must be submitted as separate files.

\section{Tables}

Tables must be submitted typewritten in the order corresponding to their first citation in the text and accompanied by brief titles. All non-standard abbreviations must appear below the table with an accompanying definition.

\section{Illustrations and Figures}

Figures and legends should contain sufficient information such that each figure is intelligible without reference to the text. If illustrations or photographs are used, they must be submitted in electronic format separate from the manuscript. Full instructions are available on the MJM website (see below).

\section{REFERENCES}

Reference citations should appear in Vancouver style (http://www.nlm.nih.gov/bsd/uniform_requirements.html). They should be numbered in parentheses throughout the text and listed in their order of appearance. Papers accepted but not yet published may appear with the name of the journal followed by the words "In press." Should these instructions not be followed, the paper may be returned to you for proper formatting. List all authors when six or less; otherwise list only first three and add et al. First author's last name, initials, second author's last name, initials, etc. Title of article. Name of Journal Volume. Year; Volume (issue): inclusive pages.

\section{EDITORIAL REVIEW PROCESS}

All submissions of "peer reviewed articles" undergo a formal and anonymous evaluation process conducted by the MJM Editorial Board, comprised of trained students with diverse areas of expertise. This peer review process is performed in two stages. During the first stage, the manuscript is evaluated individually by each member of the Editorial Board. For submissions requiring revision, a detailed manuscript evaluation summary is returned to the author with suggestions for improvement. Manuscripts of high caliber proceed to the second stage, in which a review is performed by a McGill medical faculty member whose field of expertise correlates with the subject matter of the paper. Comments from the faculty expert are synthesized with the evaluations of the Editor-in-Chief, Executive and Senior editors, and members of the Editorial Board to achieve a decision to accept, defer, or reject the paper for publication. In all cases, a detailed manuscript evaluation summary is returned to the author along with any suggestions for revision.

After appropriate revision, the manuscript text must be resubmitted and a copyright transfer agreement signed. Prior to publication, authors will be required to review edited proofs without delay.

\section{SUBMISSION OF MANUSCRIPTS}

Manuscripts must be submitted by e-mail in MS Word format to mjm.med@mcgill.ca. You may contact the McGill Journal of Medicine through the Faculty of Medicine, McGill University, 6th floor 3655 Promenade Sir William Osler, Montreal, Quebec, Canada H3G 1Y6. The MJM Editorial Division may also be contacted by telephone at (514) 398-6987, or by e-mail at mjm.med@mcgill.ca.

This is an abridged version of the instructions to authors. For the full version, please visit our website, wWw.medicine.mcgill.ca/MJM or contact us as indicated above. 